\title{
ANALISIS SPASIAL KEMISKINAN DENGAN PENDEKATAN GEOGRAPHICALLY WEIGHTED REGRESSION: STUDI KASUS KABUPATEN PANDEGLANG DAN LEBAK
}

\author{
Analysis Spatial of Poverty using Geographically Weighted \\ Regression Approach: Case Study of Pandeglang and Lebak \\ Regencies
}

\section{Sukanto ${ }^{1}$, Bambang Juanda ${ }^{2}$, Akhmad Fauzi ${ }^{2}$ and Sri Mulatsih ${ }^{2}$}

Diterima: 5 Maret 2018 Disetujui: 17 Agustus 2018

\begin{abstract}
Abstrak Kemiskinan masih menjadi permasalahan utama dalam pembangunan baik di tingkat nasional maupun daerah. Program penanggulangan kemiskinan yang dilakukan belum memperhatikan aspek spasial sehingga kebijakan yang diambil sering kurang tepat sasaran. Penelitian ini bertujuan untuk melihat pola spasial kemiskinan di Kabupaten Pandeglang dan Lebak. Metode yang digunakan adalah geographically weighted regression (GWR) dengan data kemiskinan tahun 2016. Hasil studi menunjukkan adanya autokorelasi spasial positif dan berkelompok pada 25 kecamatan. Variabel angka partisipasi murni cenderung menurunkan kemiskinan di semua kecamatan. Sementara itu, variabel dana desa, listrik dan jalan cenderung menurunkan angka kemiskinan pada lebih dari 80\% kecamatan. Respon terhadap variabel bebas berbeda di setiap kecamatan amatan. Oleh karena itu, program pengentasan kemiskinan tiap kecamatan disesuaikan dengan masing-masing faktor yang berpengaruh.
\end{abstract}

Kata Kunci: Spasial Autokorelasi, GWR, Kemiskinan, Kecamatan

\begin{abstract}
Poverty is a main problem both at the national and regional development. Existing poverty alleviation programs have not paid attention to the spatial aspect, thus the policies are often poorly targeted. This study aims to find spatial patterns of poverty in Pandeglang and Lebak districts. Geographically weighted regression (GWR) are used to analysis poverty data of 2016. Based on the analysis, positive spatial autocorrelation are found and clustered in 25 sub-districts. Net enrollment rates tend to reduce poverty in all sub-districts. Meanwhile, village funds, electricity and roads tend to reduce poverty rates in more than $80 \%$ of sub-districts. Independent variables has different response in each sub-district. Therefore, the poverty alleviation program of each sub-district is adjusted to its influencing factor.
\end{abstract}

Keywords: Autocorrelation spatial, GWR, poverty, sub-district

\section{PENDAHULUAN}

Kemiskinan masih menjadi fokus utama bagi setiap negara khususnya negara berkembang. Pada tingkat dunia, agenda pengurangan kemiskinan terlihat dari dokumen

\footnotetext{
${ }^{1}$ Program Studi Ekonomi Pembangunan Fakultas Ekonomi, Universitas Sriwijaya

${ }^{2}$ Program Studi Ilmu Perencanaan Pembangunan Wilayah dan Perdesaan, Institut Pertanian Bogor
} 
sustainability development goals (SDGs) tahun 2015. Pemerintah Indonesia pun menjadikan kemiskinan sebagai permasalahan utama untuk dituntaskan. Berbagai kebijakan dan program telah dilakukan pemerintah untuk menanggulangi kemiskinan. Program-program tersebut seperti: Program Inpres Desa Tertinggal (IDT), Program Keluarga Harapan (PKH), Kredit Usaha Tani Rakyat (KUR), Beras Miskin (Raskin) dan Jaminan Kesehatan Masyarakat (JAMKESMAS) akan tetapi hasilnya masih belum optimal (Rofiq, 2014). Selain program-program tersebut, pemerintah juga menambah anggaran melalui dana transfer daerah dan desa yang diperkuat oleh Undang-Undang No.6/2014 tentang desa. Pemerintah memberikan dana desa dengan harapan angka kemiskinan dapat berkurang terutama di daerah perdesaan. Hal ini berkaitan dengan Nawacita Presiden Jokowi khususnya pada poin ke-3 yaitu membangun Indonesia dari pinggiran dengan memperkuat daerah-daerah dan desa.

Program pengentasan kemiskinan tersebut secara masif telah dimulai sejak tahun 1990an, akan tetapi angka kemiskinan masih relatif tinggi seperti yang terjadi pada Provinsi Banten khususnya Kabupaten Pandeglang dan Kabupaten Lebak. Tingkat kemiskinan Provinsi Banten menunjukkan variasi spasial, persentase kemiskinan Provinsi Banten tahun 2015 sebesar 6,31\%. Sementara itu angka kemiskinan di Kabupaten Pandeglang dan Kabupaten Lebak masing-masing 10,33\% dan 9,59\% (BPS, 2016). Indikator mutu manusia yang diukur dengan Indeks Pengembangan Manusia (IPM) untuk kedua kabupaten juga rendah yaitu 62,72 dan 62,03 sedangkan IPM provinsi sudah di atas 70 .

Selama ini penelitian mengenai faktor-faktor penyebab kemiskinan sebagian besar menggunakan metode regresi global dengan mengabaikan aspek spasial (Ali et al. 2007). Dalam regresi global, hubungan variabel bebas terhadap variabel independen diberlakukan sama untuk semua lokasi. Menurut Brunsdon et al. (1998); Fotheringham et al. (2002); Saefuddin et al. (2011) persamaan global akan memberikan informasi yang reliabel untuk wilayah lokal bila terdapat sedikit keragaman antarwilayah lokalnya. Namun pada kenyataannya kondisi wilayah berbeda dengan daerah lainnya. Indonesia dikenal dengan wilayah kepulauan yang berimplikasi pada perbedaan tingkat ekonomi, pendidikan, kesehatan dan infrastruktur atau pun kelembagaan di setiap wilayah. Keragaman tersebut menjadi tantangan tersendiri dalam kebijakan pembangunan (Ranis dan Stewart, 1994).

Menurut Anselin (1988) pengamatan di suatu lokasi bergantung pada pengamatan di lokasi lain yang berdekatan sehingga segala sesuatu saling berhubungan. Sesuatu yang lebih dekat akan lebih berpengaruh daripada sesuatu yang jauh. Rodriquez and Pose (1998); (Rustiadi et al. (2011); Hermes et al. (2017) mengungkapkan aspek wilayah sangat penting dalam pembangunan khususnya bidang sosial-ekonomi dan perubahan sosial. Untuk itu perlu ada upaya pendekatan analisis yang melibatkan unsur spasial untuk mengolah data kemiskinan (Saefuddin et al. 2011; Sinaga, 2015; Vasan dan Alcantara, 2016). Permasalahan penelitian ini yaitu bagaimana pola spasial kemiskinan di Kabupaten Pandeglang dan Lebak. Tujuan penelitian untuk menganalisis pola spasial kemiskinan. Hal ini bermanfaat untuk perencanaan pembangunan agar program pengentasan kemiskinan lebih tepat sasaran dan sesuai dengan kondisi wilayah.

\section{METODE}

Data yang digunakan dalam penelitian ini adalah data sekunder tahun 2015 untuk variabel independen sedangkan variabel dependen (kemiskinan) menggunakan data tahun 2016. Data bersumber dari Tim Nasional Percepatan Penanggulangan Kemiskinan (TNP2K), Badan Pusat Statistik (BPS), Dirjen Perimbangan Keuangan Pusat dan Daerah (DJPK) serta Badan Informasi Geospasial (BIG). Analisis pemetaan kemiskinan mengunakan metode Geograhically Weighted Regression (GWR) yang diolah dengan software GIS 10.1 dan GeoDa 1.8.16.4. Penggunaan metode GWR pada penelitian ini untuk 
merespon adanya pengaruh spasial (Saefuddin et al. 2012; Nashwari et al. 2017). Pemetaan terhadap kemiskinan dilakukan pada 63 kecamatan di Pandeglang dan Lebak karena kedua daerah ini relatif tertinggal dibandingkan dengan kabupaten lain dalam Provinsi Banten. Hal ini merujuk pada Peraturan Presiden Nomor 131 Tahun 2015 tentang Penetapan Daerah Tertinggal Tahun 2015-2019, dimana kedua kabupaten termasuk dalam daerah tertinggal padahal jarak kedua kabupaten dengan pusat ibu kota Republik Indonesia hanya $112,3 \mathrm{~km}$.

Variabel penelitian ini meliputi a) aspek ekonomi, b) sosial, dan c) aspek fisik yang merujuk pada faktor-faktor penyebab kemiskinan berdasarkan kriteria Bappenas (2008). Berdasarkan faktor tersebut maka variabel dalam penelitian ini yaitu dana desa, angka partisipasi murni, rumah tangga menggunakan listrik dan jalan yang dapat dilalui kendaraan roda empat. Analisis model GWR dengan formula sebagai berikut:

$$
y_{i}=\beta_{0}\left(u_{i}, v_{i}\right)+\sum_{k=1}^{\rho} \beta_{k}\left(u_{i}, v_{i}\right) x_{i k}+\varepsilon_{i}
$$

$\mathrm{y}_{\mathrm{i}} \quad=$ nilai observasi variabel respon pada kecamatan ke-i $(\mathrm{i}=1,2, \ldots, 63)$

$\mathrm{x}_{\mathrm{ik}}=$ nilai observasi variabel prediktor $\mathrm{k}$ pada kecamatan ke-i $(\mathrm{i}=1,2, . ., 63)$

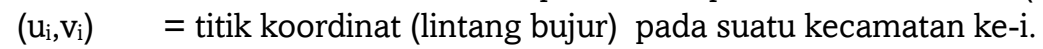

$\beta_{\mathrm{k}}(\mathrm{ui}, \mathrm{vi})=$ parameter regresi untuk setiap kecamatan ke-i

$\varepsilon_{i} \quad=$ error yang diasumsikan IIDN (identik, independen, dan berdistribusi normal) dengan mean nol dan varians konstan $\sigma^{2}$.

Identifikasi model GWR untuk kemiskinan digunakan adalah sebagai berikut:

Miskin $_{\mathrm{i}}=\beta_{0}\left(\mathrm{u}_{\mathrm{i}}, \mathrm{v}_{\mathrm{i}}\right)+\beta_{1 \mathrm{i}}\left(\mathrm{u}_{\mathrm{i}}, \mathrm{v}_{\mathrm{i}}\right) \operatorname{dandes}_{\mathrm{i}}+\beta_{2 \mathrm{i}}\left(\mathrm{u}_{\mathrm{i}}, \mathrm{v}_{\mathrm{i}}\right) \mathrm{APM}_{\mathrm{i}}+\beta_{3 \mathrm{i}}\left(\mathrm{u}_{\mathrm{i}}, \mathrm{v}_{\mathrm{i}}\right) \operatorname{List}_{\mathrm{i}}+\beta_{4 \mathrm{i}}\left(\mathrm{u}_{\mathrm{i}}, \mathrm{v}_{\mathrm{i}}\right) \mathrm{jalan}_{\mathrm{i}}+\varepsilon_{\mathrm{i}}$

Dimana:

Miskin $_{\mathrm{i}}=$ persentase penduduk miskin di kecamatan ke-i $(\mathrm{i}=1,2 \ldots, 63)$ tahun 2016

Dandes $_{\mathrm{i}}=$ dana desa per kapita (juta rupiah) di kecamatan ke-i tahun 2015

$\mathrm{APM}_{\mathrm{i}} \quad=$ persentase penduduk yang bersekolah terhadap penduduk usia sekolah di kecamatan ke-i tahun 2015

List $_{\mathrm{i}} \quad=$ persentase rumah tangga yang menggunakan listrik di kecamatan ke-i tahun 2015

$\operatorname{Jalan}_{\mathrm{i}} \quad=$ persentase jalan yang bisa dilewati kendaraan roda empat di kecamatan ke-i tahun 2015

\section{HASIL DAN PEMBAHASAN}

Hasil analisis terhadap pola kemiskinan di Kabupaten Pandeglang dan Lebak menunjukkan Indeks Moran sebesar 0.408 dengan nilai $\rho=0,000$. Nilai-p yang sangat kecil menyebabkan tolak $\mathrm{H}_{0}$ yang artinya ada ketergantungan spasial. Adanya ketergantungan spasial mengindikasikan kemiskinan satu kecamatan bergantung pada kecamatan lainnya di kedua kabupaten. Nilai Indeks Moran yang bertanda positif menunjukkan ada autokorelasi spasial positif dan berkelompok pada kemiskinan. Pola spasial positif dimaknai bahwa terjadi klasterisasi kemiskinan pada kecamatan yang memiliki nilai pengamatan kemiskinan relatif sama dan letaknya saling berdekatan atau bertetangga (Anselin, 1988; Duncan et al. 2013). Hasil GWR juga menunjukkan nilai $R 2$ adjusted sebesar 0.540, artinya $54 \%$ variasi kemiskinan mampu dijelaskan oleh variabel dalam penelitian.

Pengaruh spasial dapat terjadi tidak hanya pada satu lokasi akan tetapi bisa menyebar di berbagai lokasi dalam kecamatan amatan. Sebaran pengaruh spasial dalam penelitian ini diidentifikasi dengan teknik analisis Local Indicators of Spatial Association (LISA). Analisis LISA menunjukkan adanya autokorelasi spasial di 25 kecamatan dengan tingkat signifikansi 0,001 sampai dengan 0,05 (Gambar 1a dan 1b). Kuadran I, menjelaskan kecamatan dengan kemiskinan tinggi dikelilingi oleh kecamatan yang memiliki kemiskinan tinggi $(\mathrm{H}-\mathrm{H})$, kuadran II merupakan kecamatan dengan kemiskinan rendah, namun 
dikelilingi oleh wilayah dengan kemiskinan tinggi (L-H); kuadran III menunjukkan kecamatan dengan kemiskinan rendah dan dikelilingi oleh kecamatan dengan kemiskinan rendah (L-L); kuadaran IV (H-L) menunjukkan kecamatan dengan kemiskinan tinggi dan dikelilingi oleh kecamatan juga dengan kemiskinan rendah (Hermes et al. 2017).

Kecamatan yang termasuk dalam kuadaran I $(\mathrm{H}-\mathrm{H})$ meliputi Kecamatan Mandalawangi, Jiput, Pulosari, Cisata, Seketi, Cipeucang, Kaduhejo, dan Cikeusik (Kabupaten Pandeglang). Kecamatan-kecamatan tersebut relatif memiliki tingkat kemiskinan yang tinggi dan dikelilingi juga oleh kecamatan yang memiliki kemiskinan yang tinggi. Hal ini mengindikasikan ada pengaruh spasial pada kemiskinan di daerah amatan (Amara and Ayadi, 2013). Wilayah yang termasuk dalam kuadran II (L-H) yaitu Kecamatan Cimanggu, Sobang, Menes (Kabupaten Pandeglang). Hasil klasterisasi kuadaran III (L-L) terdiri atas Cijaku, Panggarangan, Bayah, Cilograng, Cibeber, Cipanas, Sajira, Cimarga, Kalang Anyar, Rangkas Bitung, Cibadak, Cikulur, Warung Gunung, Maja (Kabupaten Lebak) dan Kuadran IV (H-L) yaitu Kecamatan Leuwidamar (Kabupaten Lebak).

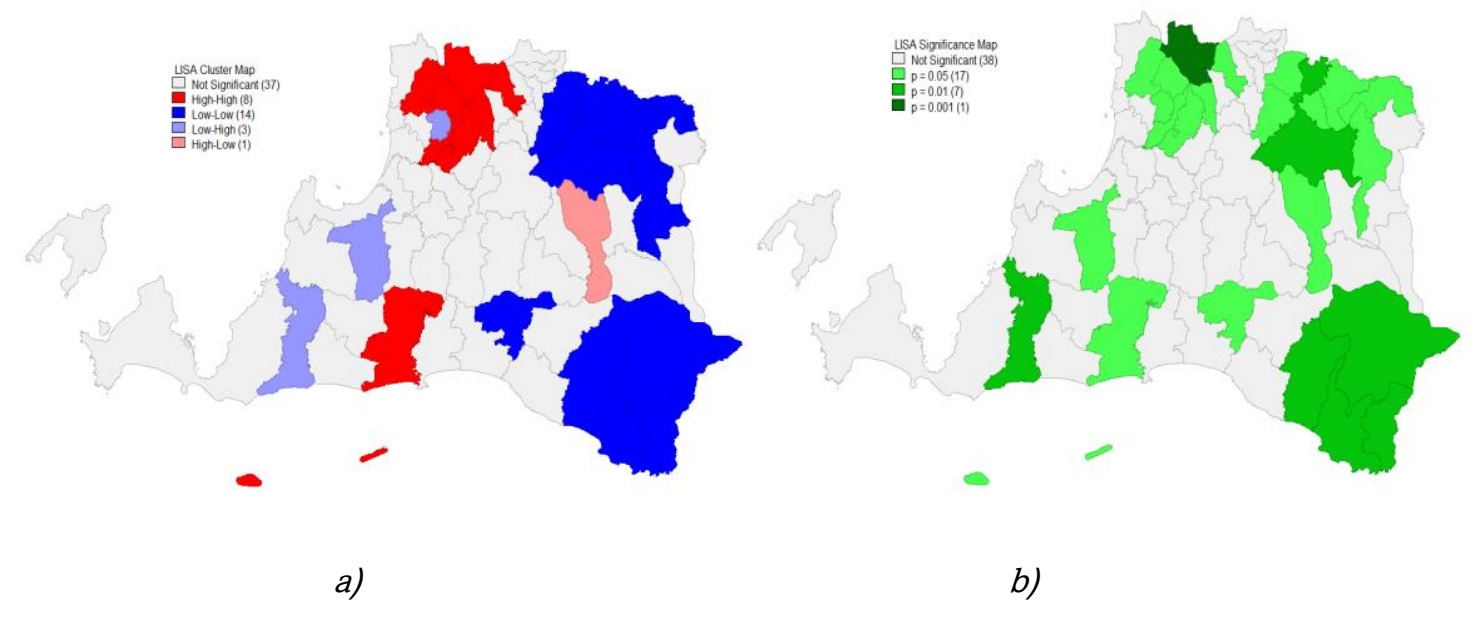

Sumber: hasil olahan penulis (2017)

Gambar 1 (a) Spasial autokorelasi kemiskinan, (b) Spasial Siqnifikansi kemiskinan

Adanya autokorelasi parsial atau konsentrasi spasial kemiskinan di dua kabupaten tersebut menunjukkan bahwa kebijakan/program tidak bisa disamaratakan. Hasil identifikasi menggunakan LISA mengisyaratkan bahwa dalam menurunkan angka kemiskinan perlu diprioritaskan pada wilayah-wilayah memiliki kemiskinan tinggi (H-H), (H-L) dan (L-H). Data publikasi TNP2K tahun 2015 menujukkan terdapat 22 kecamatan yang masih memiliki tingkat kemiskinan diatas 10 persen, dimana lebih dari separuh jumlah tersebut terdapat di Kabupaten Pandeglang. Program pengentasan kemiskinan perlu diprioritaskan pada kantong kemiskinan yang tinggi tersebut.

Hasil analisis Indeks Moran dan LISA telah secara jelas menunjukkan pola kemiskinan di Kabupaten Pandeglang dan Lebak namun belum mampu mengidentifikasi faktor penyebab kemiskinan sehingga penelitian ini perlu menggali faktor penyebab kemiskinan. Hal ini penting agar kebijakan yang diambil lebih tepat sasaran. Hasil estimasi model GWR menunjukkan respon variabel bebas (dana desa, APM, listrik, dan jalan) bervariasi di setiap wilayah. Hasil tersebut menguatkan argumen bahwa aspek spasial tidak dapat diabaikan dalam pembangunan daerah khususnya pengentasan kemiskinan. Oleh karena itu, kebijakan yang diambil perlu memperhatikan keragaman wilayah (Khan, 2013; Wahyuni dan Damayanti, 2014) 
Temuan penelitian menggunakan GWR ini memberikan informasi bahwa variabel pendidikan (angka partisipasi murni) cenderung mampu mengurangi angka kemiskinan di semua kecamatan yang ada di kedua kabupaten dengan interval koefisien -0,3704 sampai dengan -1,0818 (Gambar 2). Data BPS tahun 2015 mengambarkan bahwa angka partisipasi di kedua kabupaten untuk jenjang pendidikan SMP dan SMA relatif masih kecil. APMSMP di Kabupaten Pandeglang sebesar 69,39 dan Kabupaten Lebak sebesar 67,98 sedangkan APMSMA masih rendah yaitu masing-masing sebesar 43,63 dan 38,81. Melihat adanya hubungan yang kuat antara tingkat pendidikan dan kemiskinan, maka pemerintah daerah perlu memprioritaskan bidang pendidikan untuk meningkatkan nilai APM sehingga angka kemiskinan dapat menurun. Hasil ini mendukung penelitian Hidalgo and Ormaetxe (2014) yang mengungkapkan pengeluaran sektor pendidikan berpengaruh terhadap kemiskinan. Sejalan dengan itu Chen dan Wang (2015); Mai dan Mahadevan (2016); Bici dan Cela (2017) mengatakan bahwa pendidikan menjadi faktor penting dalam pengentasan kemiskinan melalui perbaikan sumberdaya manusianya (human capital).

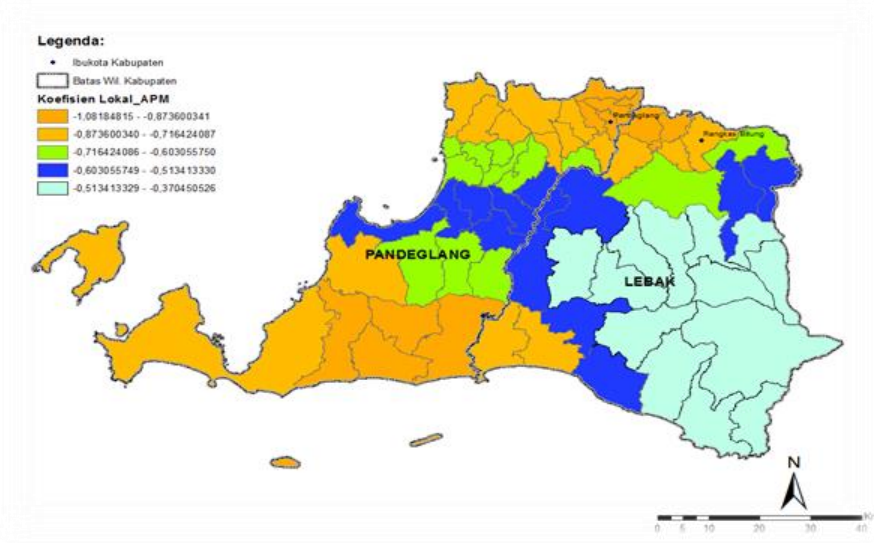

Sumber: hasil olahan penulis (2017)

\section{Gambar 2. $\beta_{2 i}\left(u_{i}, v_{i}\right)$ Agka partisipasi murni}

Sementara itu, variabel dana desa cenderung menurunkan angka kemiskinan pada lebih dari $80 \%$ kecamatan di kedua kabupaten. Namun demikian, hasil studi ini juga menunjukkan bahwa ada penggunaan dana desa belum diiringi oleh penurunan angka kemiskinan. Hal ini terlihat pada 8 kecamatan di Kabupaten Pandeglang yaitu Kecamatan Cigeulis, Panimbang, Sobang, Pagelaran, Sukaresmi, Labuan, Carita, Cikedal (Gambar 3). Secara topografi 8 kecamatan tersebut berada di wilayah daerah pesisir pantai barat. Kabupaten Pandeglang merupakan salah satu kabupaten tertinggal di Provinsi Banten dengan tingkat kemiskinan pada tahun 2015 sebesar 10.33\%.

Berdasarkan penelitian Yudha (2017) yang menyatakan bahwa pengelolaan dana desa di Kabupaten Pandeglang berfokus pada sarana dan prasana seperti yang disyaratkan undang-undang sehingga berdampak pada meningkatnya arus barang dan jasa. Hal ini menyebabkan modal yang mengalir ke desa tidak sepenuhnya dinikmati oleh masyarakat (capital outflow) atau ada indikasi kebocoran wilayah (Rustiadi et al. 2011). Oleh karena itu, merujuk pada Permendes PDTT No.5/2015 yang menyatakan bahwa salah satu prioritas dana desa adalah pembangunan desa dengan tujuan untuk menanggulangi kemiskinan melalui pembangunan sarana dan prasarana serta pengembangan potensi ekonomi lokal. Kedepan, penggunaan dana desa perlu difokuskan pada pengembangan potensi ekonomi lokal seperti pembenahan kelembagaan pertanian dan pariwisata sehingga dana desa dapat lebih berkontribusi terhadap pembangunan dan pengembangan daerah. Hasil studi Yudha 
(2017) juga menemukan bahwa diperlukan optimalisasi fungsi pendamping desa agar pemanfaatan dana desa menjadi lebih efisien dan tepat sasaran.

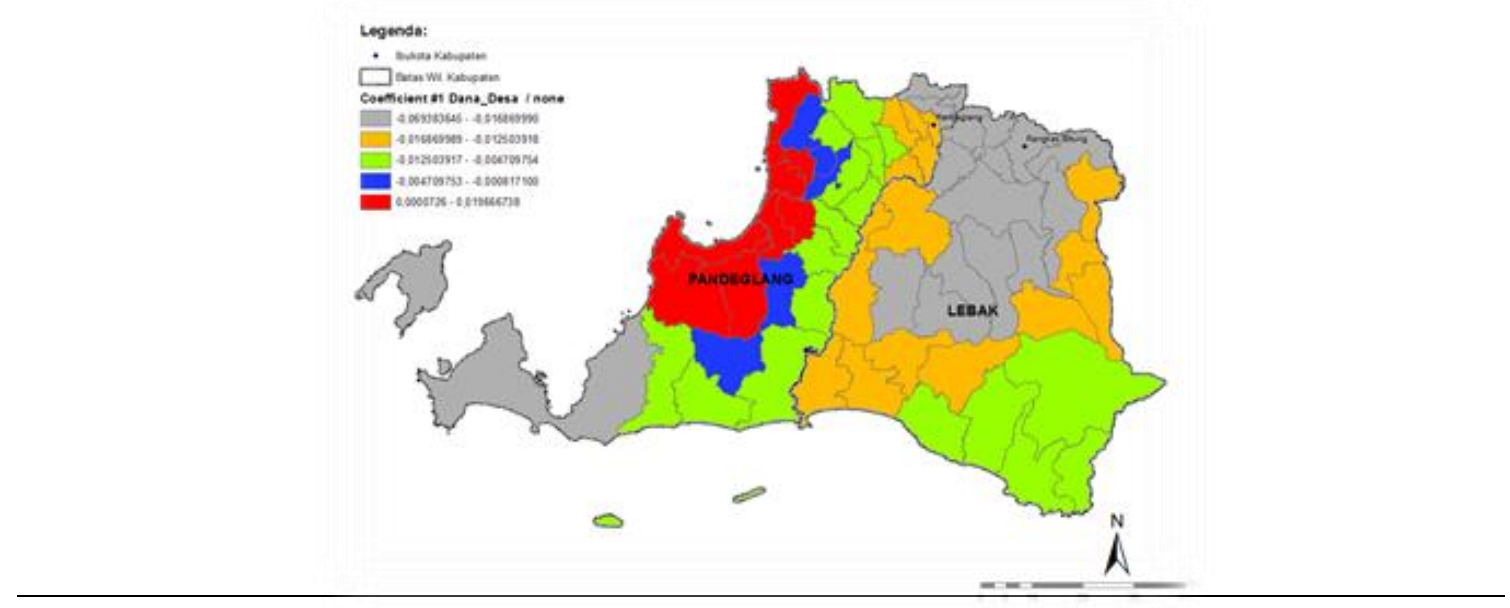

Sumber: olahan penulis (2017)

Gambar 3. $\beta_{1 i}\left(u_{i}, v_{i}\right)$ dana desa $a_{i}$

Secara umum infrastruktur sangat berperan dalam pembangunan daerah seperti ditunjukkan oleh penelitian Yu et al. (2011); Sasmal dan Joydeb (2016) di Cina, Yusuf dan Sumner (2015) di Indonesia serta Alinsato (2015) yang menyatakan infrastruktur merupakan faktor penting dalam peningkatan produktifitas dan efisiensi pertanian sehingga mampu mengurangi tingkat kemiskinan. Hasil studi ini menunjukkan bahwa secara spasial variabel listrik cenderung menurunkan kemiskinan di 56 kecamatan (Gambar 5a). Hasil tersebut sejalan dengan studi Pongoh et al. (2015) menyatakan rumah tangga yang menggunakan listrik berpengaruh terhadap kemiskinan di Sulawesi Selatan. Demikian juga, hasil Kajian Dreibelbis et al. (2013) menunjukkan adanya hubungan tidak langsung antara tersedianya akses listrik terhadap penurunan angka kemiskinan. Namun, hasil estimasi penelitian ini juga menemukan bahwa variabel listrik belum menurunkan angka kemiskinan 7 kecamatan. Ketujuh kecamatan tersebut adalah Kecamatan Labuan, Carita, Jiput, Pulosari, Mandalawangi, Cadasari, dan Karang Tanjung. Diperlukan peningkatan akses pada jaringan yang dimiliki PLN bagi rumah tangga yang belum dialiri listrik. Data TNP2K tahun 2015 menunjukkan, sebanyak 2.100 rumah tangga belum dialiri listrik PLN di Kabupaten Pandeglang dan sebanyak 2.605 rumah tangga di Kabupaten Lebak.

Hasil estimasi terhadap infrastruktur jalan menunjukkan bahwa keberadaan jalan (dapat dilalui kendaraan roda empat) cenderung menurunkan kemiskinan di 53 kecamatan yang tersebar di Kabupaten Pandeglang dan Lebak (Gambar 5b). Penelitian Damania et al. (2017) di negara Republik Demokratik Kongo menemukan bahwa infrastruktur jalan secara signifikan membawa keuntungan bagi pembangunan. Secara lebih fokus Edriss and Chiunda (2017) yang melakukan penelitian di Negara Malawi; menyatakan pembangunan infrastruktur jalan dapat mendorong perkembangan desa dan menurunkan angka kemiskinan. Namun, hasil estimimasi juga menemukan hal sebaliknya di 10 kecamatan yaitu Kecamatan Sumur, Cimanggu, Cibaliung, Cibitung, Cikeusik, Cigeulis, Panimbang, Sobang, Angsana (Kabupaten Pandeglang), dan satu kecamatan di Kabupaten Lebak yaitu Kecamatan Wanasalam. Data BPS tahun 2014 menunjukkan masih terdapat jalan yang belum bisa dilalui kendaraan roda empat di wilayah Kabupaten Pandeglang diantaranya Kecamatan Cibaliung, Cibitung, Cikeusik, Ciguelis, Sobang, Angsana serta di Kabupaten Lebak antara lain di Kecamatan Wanasalam. Pemerintah daerah perlu meningkatkan 
aksestabilitas terhadap daerah-daerah yang masih terisolasi. Program pembangunan dapat di fokuskan pada jalan di area perdesaan dan jalan usaha tani sehingga dapat meningkatkan penghasilan bagi masyarakat miskin dan mengurangi pengeluaran mereka karena rendahnya biaya transportasi untuk menjual produk hasil pertanian.

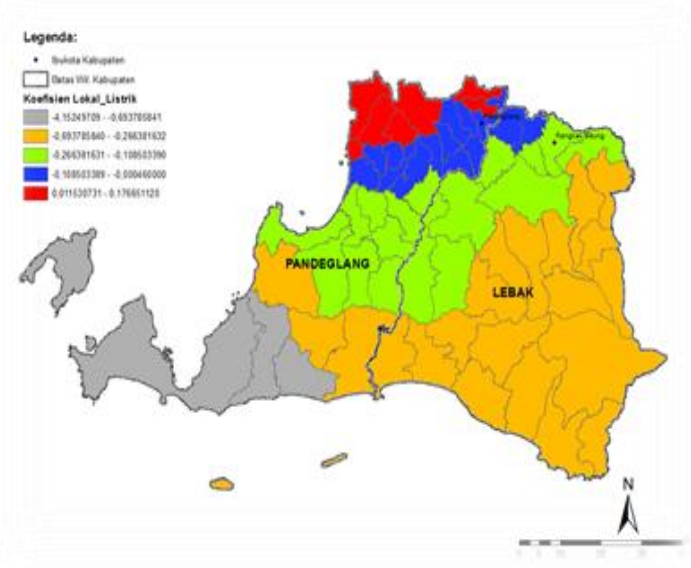

a)

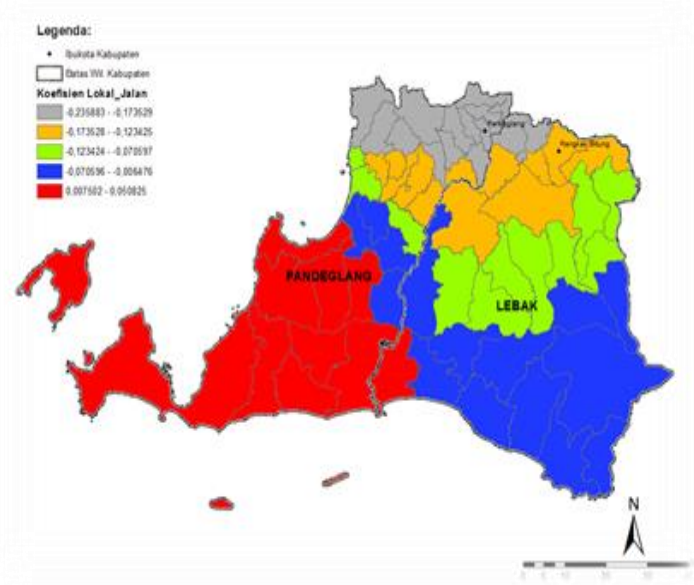

a)

Sumber: hasil olahan penulis (2017)

Gambar 5. a) $\beta_{3 i}\left(u_{i}, v_{i}\right) L_{i s t r i k}$, (b) $\beta_{4 i}\left(u_{i}, v_{i}\right) j a l a n_{i}$

\section{KESIMPULAN}

Hasil Indeks Moran's dan LISA menunjukkan adanya pola spasial positif dan berkelompok pada data kemiskinan di Kabupaten Pandeglang dan Kabupaten Lebak. Berdasarkan hasil estimasi GWR secara spasial APM, dana desa, listrik dan jalan menunjukkan pengaruh berbeda di setiap wilayah. Hal ini mengindikasikan adanya pengaruh spasial terhadap kemiskinan. Hasil tersebut menguatkan argumen bahwa aspek spasial tidak dapat diabaikan dalam pembangunan daerah khususnya pengentasan kemiskinan. Oleh karena itu, pengentasan kemiskinan berbasis wilayah dapat dijadikan dasar penentuan/penetapan kebijakan agar dapat lebih tepat sasaran. Hal ini dapat dilakukan melalui sinergisitas kebijakan dan program penanggulangan kemiskinan agar tidak terjadi tumpang tindih kegiatan di lokasi yang sama. Kebijakan penanggulangan kemiskinan dapat diprioritaskan pada peningkatan angka partisipasi murni (APM) untuk semua kecamatan terutama peningkatan APMSMP dan APMSMA di Kabupaten Pandeglang dan Kabupaten Lebak. Selain itu, kebijakan pemerintah daerah diarahkan pada optimalisasi dana desa melalui fungsi pendamping dana desa, peningkatan infrastruktur jalan, dan listrik yang disesuaikan dengan kebutuhan daerah.

\section{DAFTAR PUSTAKA}

Ali K, Partridge MD, Olfert MR. 2007. Can Geographically Weighted Regressions Improve Regional Analysis and Policy Making?. International Regional Science Review. 30(3):300-329. https://doi.org/10.1177/0160017607301609.

Alisanto AS. 2015. Globalization, Poverty and Role of Infrastructures. Journal of Economics and Political Economy. 2 (1s):197-212. https://doi.org/10.1453/jepe.v2i1s.225.

Amara M, Ayadi M. 2013. The Local Geographies of Walfare in Tunisa: Does Neighbourhood Matter?. International Journal of Social Walfare. 22 (1):90-103.

Anselin L. 1988. Spatial Econometrics: Method and Models. Dordrect Boston (US): Kluwer Academic Publiser. 
Bappenas. 2008. Buku Panduan Perencanaan dan Penganggaran yang Berpihak Pada Masyarakat Miskin. Jakarta (ID): Badan Perencanaan Pembangunan Nasional.

Bici R, Cela M. 2017. Education as An Important Dimension of the Poverty. European Journal of Multidisciplinary Studies. 8385:88-95.

BPS. 2016. Indikator Kesejahteraan Rakyat 2016. Jakarta (ID): Badan Pusat Statistik.

Brunsdon C, Fotheringham S, Chariton M. 1998. Geographically Weighted Regression-Modelling Spatial NonStationarity. Journal of Royal Statistical Society: Series D(The Statistican). 47(3):431-443.

Chen KM, Wang TM. 2015. Determinants of Poverty Status in Taiwan: A Multilevel Approach. Social Indicators Research. 123 (2):371-389. https://doi.org/10.1007/s11205-014-0741-4.

Damania R, Russ J, Wheeler D, Federico A. 2017. The Road to Growth: Measuring the Tradeoffs between Economic Growth and Ecological Destruction. World Development xx. https://doi.org/10.1016/j.worlddev.2017.06.001.

Dreibelbis R, Greene LE, Freeman MC, Saboori S, Chase RP, Rheingans R. 2013. Development Water, Sanitation, and Primary School Attendance: A Multi-Level Assessment of Determinants of HouseholdReported Absence in Kenya. International Journal of Educational Development 33 (5). 457-465. https://doi.org/10.1016/j.ijedudev.2012.07.002.

Duncan DT, Kawachi I, White K, Williams DR. 2013. The Geography of Recreational Open Space: Influence of Neighborhood Racial Composition and Neighborhood Poverty. Journal of Urban Health. 90 (4):618631. https://doi.org/10.1007/s11524-012-9770-y.

Edriss AK, Chiunda C. 2017. Interfaces Between Road Infrastructure and Poverty in Africa: The Case of Malawi, 1994-2013. Journal of Social Economics Research. 4(1):9-21. https://doi.org/10.18488/journal.35.2017.41.9.21.

Fotheringham A, Lu B, Charlton M, Harris P, Stewart A. 2002. Geographically Weighted Regression: The Analysis of Spatially Varying Relationships Data. International Journal of Geographical Information Science. 1-22. https://doi.org/10.1080/13658816.2013.865739.

Hermes, Juanda B, Rustiadi E, Barus B. 2017. Pemetaan Efek Spasial Pada Data Kemiskinan Kota Bengkulu. Journal of Regional and Rural Development Planning. 1(2):192-201.

Hidalgo HM, Ormaetxe II. 2014. Long-Run Effect on Poverty of Public Expenditure in Education. Working Paper. AD(2014-06):1-38.

Khan FC. 2013. Heterogeneity as Heterodoxy in Development Policy: Tribal Communities in Bangladesh and Kerela. International Journal of Development Issues. 12 (1):4-21.

Mai T, Mahadevan R. 2016. A Research Note on the Poverty Dynamics and Cost of Poverty Inequality: Case Study of Indonesia. Economic Analysis and Policy. 49:100-107 https://doi.org/10.1016/j.eap.2015.12.003.

Nashwari IP, Rustiadi E, Siregar H, Juanda B. 2017. Geographically Weighted Regression Model for Poverty Analysis in Jambi Province. Indonesian Journal of Geography. 49 (1):42-50.

Pongoh F, Sumertajaya IM, Aidi MN. 2015. Geographichal Weighted Regression and Mix Geographichal Weighted Regression. International Journal of Stastistics and Application. 5(1):1-4. https://doi.org/10.5923/j.statistics.20150501.01.

Ranis G, Stewart F. 1994. Decentralization in Indonesia. Bulletin of Indonesian Economic Studies. 30(3):41-72.

Rodriquez, Pose A. 1998. The Dynamics of Regional Growth in Europe: Social and Political Factors. New York (US): Oxford Clarendon.

Rofiq, A. 2014. Pertumbuhan Ekonomi dan Kemiskinan Kebijakan dan Tantangan Masa Depan. Jakarta (ID): Republika.

Rustiadi E, Sunsun S, Dyah DP. 2011. Perencanaan dan Pengembangan Wilayah. Jakarta (ID): Crespent Press dan Yayasan Pustaka Obor Jakarta.

Saefuddin A, Setiabudi N, Achsani N. 2011. On Comparisson between Ordinary Linear Regression and Geographically Weighted Regression: With Application to Indonesian Poverty Data. European Journal of Scientific Research 57 (2):275-285.

Saefuddin A, Setiabudi NA, Fitrianto A. 2012. On Comparison Between Logistic Regression and Geographically Weighted Logistic Regression: With Application to Indonesian Poverty Data. World Applied Sciences Journal. 19(2):205-210. https://doi.org/10.5829/idosi.wasj.2012.19.02.528.

Sasmal R, Joydeb S. 2016. Public Expenditure, Economic Growth and Poverty Alleviation. International Journal of Social Economics. 43 (6):604-618.

Sinaga KP. 2015. Poverty Data Modeling in North Sumatera Province Using Geographically Weighted Regression (GWR) Method. Internation Journal of Science and Research (IJSR). 4(2): 1738-1742. 
Vasan S, Alcantara A. 2016. Review of Economics \& Finance GIS-Based Methods for Estimating Missing Poverty Rates \& Projecting Future Rates in Census Tracts. Review of Economics \& Finance. 6:1-13.

Wahyuni RNT, Damayanti A. 2014. Faktor-Faktor yang Menyebabkan Kemiskinan di Provinsi Papua: Analisis Spatial Heterogeneity. Jurnal Ekonomi dan Pembangunan Indonesia. 14(2):128-144.

Yu Y, Zhang L, Li F, Zheng X. 2011. On the Determinants of Public Infrastructure Spending in Chinese Cities: A Spatial Econometric Perspective. The Social Science Journal. 48 (3):458-67. https://doi.org/10.1016/j.soscij.2011.05.006.

Yudha EP. 2017. Implementasi Pengelolaan Keuangan Desa Dan Pengaruhnya Terhadap Kinerja Pembangunan Perdesaan: Studi Kasus Kabupaten Pandeglang-Banten. Disertasi. Bogor (ID): Institut Pertanian Bogor,.

Yusuf AA, Sumner A. 2015. Growth, Poverty and Inequality under Jokowi. Bulletin of Indonesian Economic Studies. 51 (3):323-348. https://doi.org/10.1080/00074918.2015.1110685. 